\title{
La cuenca del río Chillón: Problemática y potencial productivo
}

\section{ASPECTOS GENERALES}

El Perú es un país de gran diversidad cultural y enorme potencial turístico. Asimismo, tiene una extraordinaria variedad de recursos vivos y de ecosistemas, que hoy se conocen como diversidad biológica o biodiversidad, y por esto se encuentra entre los países más diversos del planeta, entre los que ocupa uno de los cinco primeros lugares (Brack Egg, 2004).

Parte de estas características se encuentran bien expresadas en el estudio "Evaluación preliminar con fines productivos en la cuenca del río Chillón”, que realizaron un grupo de profesores de la Universidad de Lima a partir de agosto de 1997, y sobre el cual se continúa trabajando como uno de los temas prioritarios en el ámbito nacional.

La cuenca del río Chillón se ubica en el centro-oeste del país, en el departamento de Lima, y el Chillón es uno de los tres ríos, junto con el Rímac y el Lurín, que soporta la mayor cantidad de población urbana. Al 2006, casi un tercio de los habitantes de Lima, que cuenta con más de ocho millones, se ubicaban en estas tres vertientes.

La cuenca del Chillón, recorrida por el río del mismo nombre, es de gran pendiente. Nace en un conjunto de lagunas: Pucracocha, Aguascocha y Chuchón, sobre los $4.800 \mathrm{msnm}$, y desciende hasta el nivel del mar en 126 kilómetros, cuando desemboca en el océano Pacífico. 
Limita por el norte con la cuenca del río Chancay, por el sur con la del río Rímac, por el este con la del río Mantaro y por el oeste con el océano Pacífico.

Esta cuenca es una fuente de referentes históricos, desde la época preínca hasta la republicana, y se constituye también en una importante fuente de vida para las personas que habitan en Lima norte, empleando las aguas superficiales y subterráneas para la producción de crianzas y cultivos agropecuarios.

La calidad y diversidad de sus recursos naturales, principalmente los hídricos, de flora y de fauna, permiten el sostenimiento de 3 provincias, 15 distritos y decenas de comunidades campesinas. Además, en su parte baja existen 16 fábricas industriales.

La cuenca del río Chillón es parte inmediata y natural de la relación espacial entre el núcleo metropolitano y sus alrededores. En relación con otras cuencas aledañas, tales como Chancay, Lurín y Rímac, el río Chillón cuenta con mejores recursos para la producción alimentaria, y es una de las más importantes en cuanto a potencial ecológico y turístico. La cuenca del río Chillón cuenta con el $27 \%$ de los mejores suelos de la Región Lima, que tiene aproximadamente 8.619 hectáreas.

\section{APROVECHAMIENTO DE LOS RECURSOS HÍDRICOS DE LA CUENCA DEL RÍO CHILLÓN Y DEL POTENCIAL PRODUCTIVO}

Es importante señalar algunos avances en el uso racional de los recursos por parte de la empresa privada. Es el caso de la Planta de Tratamiento de Aguas Residuales de Puente Piedra, que contribuye al tratamiento de las aguas servidas de parte del sector norte de Lima, con fines de descontaminación. Otro adelanto importante es la puesta en operación del proyecto "Optimización de las Aguas Superficiales y Subterráneas del Río Chillón”, ubicado en el distrito de Carabayllo, que está operando desde el mes de julio del 2001, mediante el abastecimiento de agua potable a los pobladores ubicados en los distritos de Comas y Carabayllo. 


\subsection{Planta de Tratamiento de Aguas Residuales de Puente Piedra (PTAR)}

La Planta de Tratamiento de Aguas Residuales de Puente Piedra entró en funcionamiento en setiembre del 2002. La tecnología usada para el tratamiento de las aguas residuales es la de lodos activados, que es un sistema biológico de depuración, gracias a la fotosíntesis, los nutrientes del ambiente y los aireadores artificiales que proveen de oxígeno para la disminución de la carga bacteriana; así, se logra una eficiencia de hasta $95 \%$. Tiene un caudal de diseño de $420 \mathrm{~L} / \mathrm{s}$ y ha sido construida con una inversión de US\$6 millones, financiada por el Banco Mundial (73\%) y con recursos propios de Sedapal (27\%). Se encuentra ubicada en la margen izquierda del río Chillón, sobre un terreno de seis hectáreas, y el efluente beneficia a miles de agricultores que residen en Lima norte, que antes regaban sus campos con aguas servidas.

A fines del 2004, la planta tenía, en promedio, una producción de agua tratada diaria de $157 \mathrm{~L} / \mathrm{s}$, lo que permite descontaminar un total de $36.460 \mathrm{~m}^{3}$ por día.

En la fotografía 1 se muestra la vista general de la PTAR de Puente Piedra.

\section{Fotografía 1}

Vista general de la PTAR de Puente Piedra

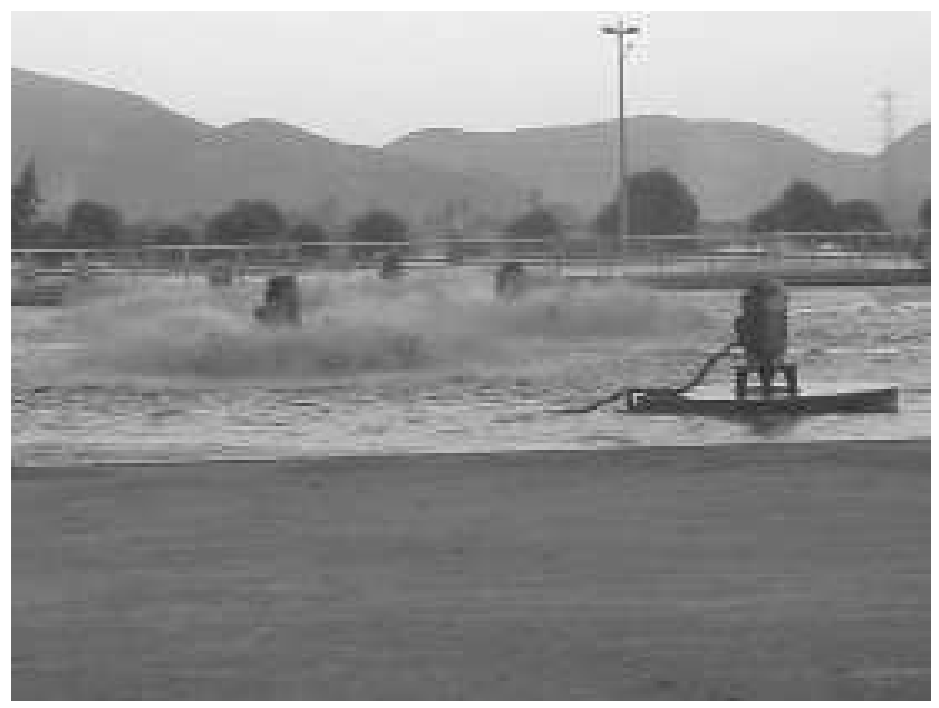

Fuente: Sedapal, 2005. 


\subsection{Optimización de las aguas superficiales y subterráneas del río Chillón}

El Consorcio Agua Azul, mediante la firma del contrato de concesión, el 7 de abril del 2000 asumió el compromiso para el desarrollo del diseño definitivo del proyecto, su construcción, mantenimiento y operación del sistema. La modalidad empresarial utilizada para este proyecto fue la denominada Build, Operate and Transfer (BOT). Una vez cumplida la vigencia de la concesión, toda la infraestructura será transferida al Estado.

La concesión consiste en la captación de las aguas superficiales y subterráneas de la cuenca del río Chillón, su tratamiento y la entrega a Sedapal para su posterior distribución a aproximadamente 750.000 habitantes en los distritos del norte de Lima (Carabayllo, Comas, Ventanilla, Ancón, Puente Piedra y Santa Rosa) a razón de $2,0 \mathrm{~m}^{3} / \mathrm{s}$ entre diciembre y abril (época de lluvias, cuando el abastecimiento proviene de aguas superficiales) y $1,0 \mathrm{~m}^{3} / \mathrm{s}$ entre mayo y noviembre (época de sequía, cuando el abastecimiento proviene de aguas subterráneas).

\section{Fotografía 2}

Vista general de la PTAR de Puente Piedra

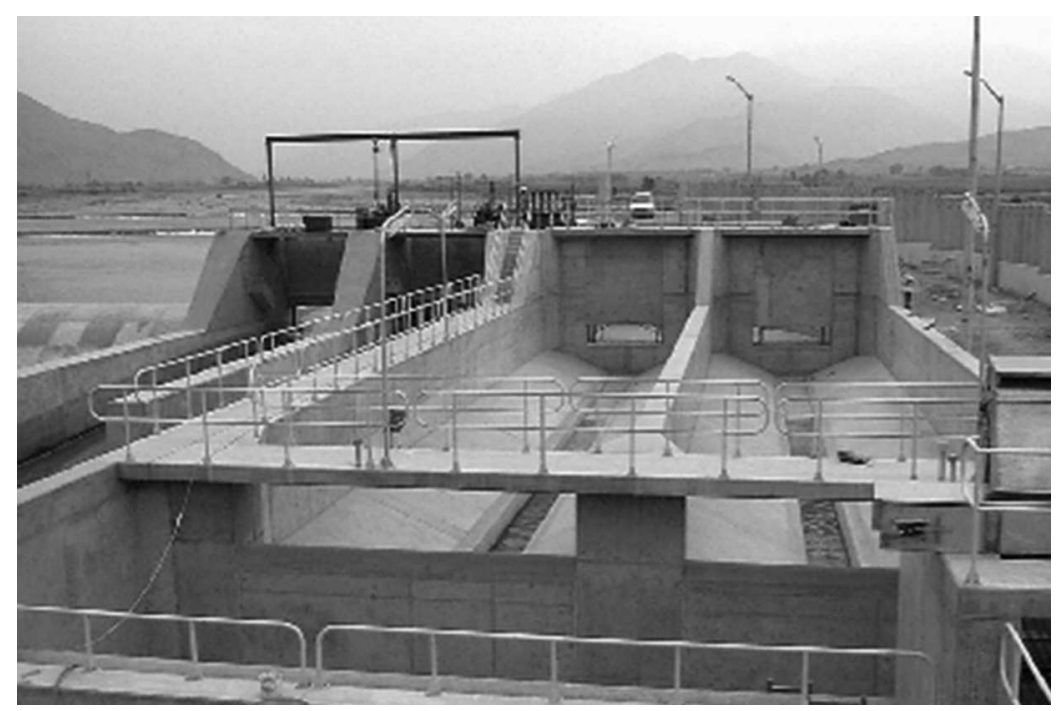

Fuente: <http://www.caa.com.pe>. 
En la fotografía 2 se muestra las instalaciones de la planta de potabilización de agua del río Chillón.

El plazo de la concesión es de 27 años contados a partir del 7 de abril del 2000 y el contrato puede ser renovado mediante acuerdo mutuo de las partes por 33 años adicionales.

\subsection{Potencial productivo}

En la provincia de Canta destacan las actividades agrícolas y pecuarias. Para el desarrollo de la primera se cuenta con una superficie de 9.736 hectáreas, de las cuales 3.650 están bajo riego y 6.326 son tierras de secano; y para la segunda existen 109.496 hectáreas de pastos naturales que en 1998 se vieron favorecidas con el fenómeno El Niño. Dos productos típicos de la cuenca alta del río Chillón son la papa huamantanga y los quesos de Pariamarca.

Es importante destacar las actividades de producción y comercialización de los quesos de cabra que realiza el consorcio formado por los productores de caprinos del valle del Chillón y la institución Procabra.

Adicionalmente existe un potencial minero en la cuenca, posible de situarse en la provincia de Canta, para extraer oro, plata y plomo en el distrito del mismo nombre. Además, en el distrito de Huamantanga se encuentran canteras de yeso, arena y granito, lamentablemente inexplotados por falta de inversión. Una de las actividades más prometedoras es la crianza de truchas, tanto porque las condiciones naturales lo permiten como por la cercanía del mercado limeño, en especial de las poblaciones de la zona norte de Lima metropolitana.

\section{LAS TRES PARTES DE LA CUENCA}

El relieve general de la cuenca es similar al de una hoya hidrográfica alargada, de fondo profundo y quebrado, de una fuerte pendiente, flanqueada por amplias cadenas de cerros. 


\subsection{La cuenca baja}

Se encuentra entre cero y $800 \mathrm{msnm}$, desde su desembocadura en el mar hasta el distrito de Carabayllo. La vegetación natural en la parte baja es escasa y en algunos cerros se forma la vegetación típica de las lomas.

Sin embargo, este sector de la cuenca es el que presenta mejores suelos para la actividad productiva, habiendo sido calificado incluso como el más rico de los 53 valles de la costa peruana. En la fotografía 3 se muestra la cuenca baja del río Chillón, donde se aprecia una fuerte presencia de población urbano-rural asentada en el acantilado de la cuenca y, consecuentemente, la contaminación del río por residuos domésticos.

\section{Cuenca baja del río Chillón}

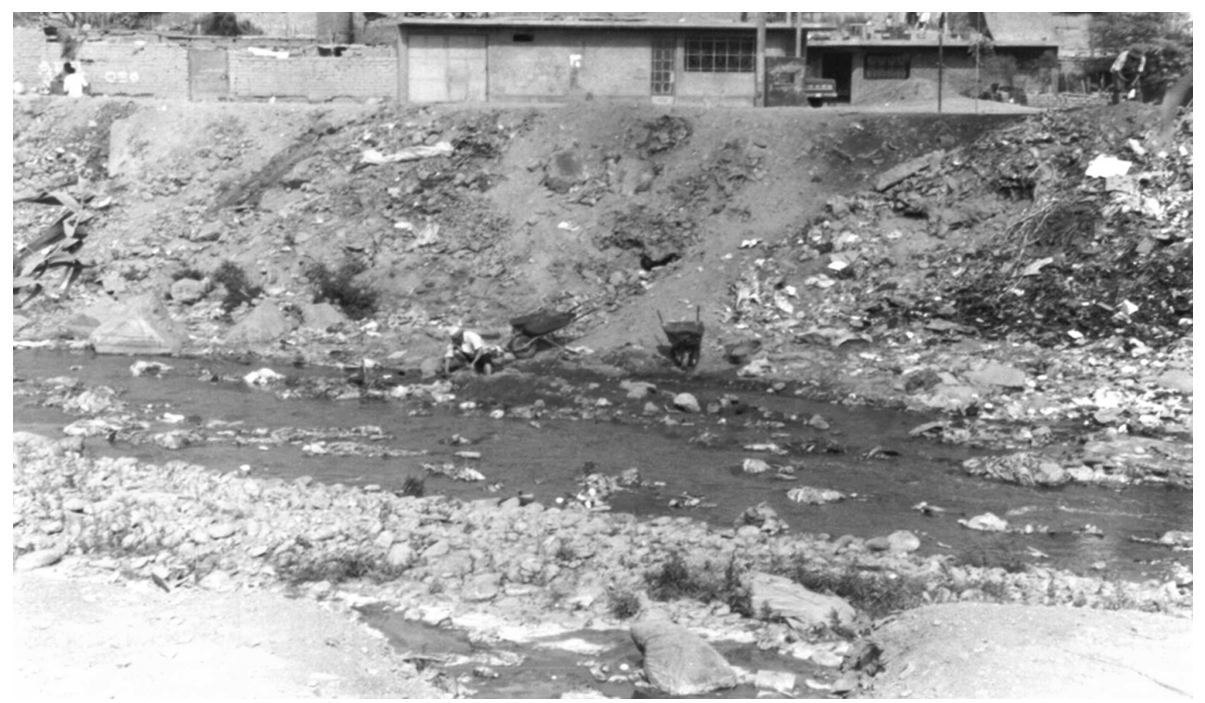

Fuente: Universidad de Lima, Centro de Estudios Ambientales, 1997. 


\subsection{La cuenca media}

Se encuentra entre los 800 y $2.500 \mathrm{msnm}$, desde el distrito de Carabayllo hasta el pueblo de Yaso.

A medida que se asciende predominan los arbustos y las cactáceas columnares, que alcanzan el verdor típico de la serranía.

La producción de cultivos se orienta en un $70 \%$ al consumo humano, con tubérculos, hortalizas y frutales; mientras que en un $10 \%$ son cultivos agroindustriales como el maíz amarillo y el algodón, entre otros.

Por su parte, la producción pecuaria no está desarrollada en todo su potencial, teniendo en cuenta la diversidad de microclimas, la superficie agrícola y las altas perspectivas de comercialización en el mercado de la capital. En la fotografía 4 se muestra una imagen del puente Inca, que tuvo que ser destruido en 1998 para proceder a la ampliación del cauce del río debido al fenómeno El Niño.

\section{Fotografia 4}

\section{Cuenca media del río Chillón}

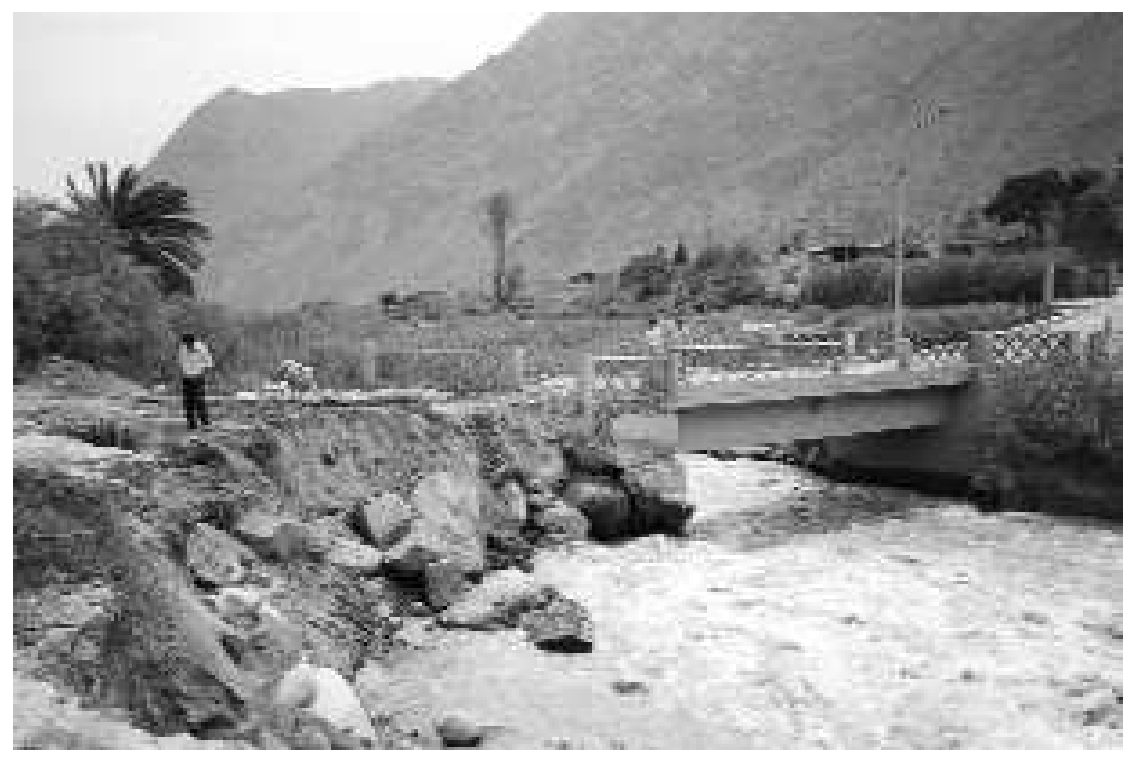

Fuente: Universidad de Lima, Centro de Estudios Ambientales, 1997. 


\subsection{La cuenca alta}

Se encuentra entre los 2.500 y $4.850 \mathrm{msnm}$, desde Yaso hasta las lagunas de Pucococha, Aguascocha y Chuchún, que dan origen al río Chillón.

En la parte alta, el paisaje dominante es típico de la puna, el clima es frío, con heladas frecuentes. El suelo se hace más ondulado, con menos pendiente, y la vegetación local es de pastos de altura y algunos bosques residuales en laderas de montaña. La fauna silvestre característica está compuesta por hatos de vicuñas, cóndores, vizcachas y otras especies. De 2.500 a $3.000 \mathrm{msnm}$, el agua limpia permite la crianza de truchas, es decir que se dan las condiciones para su desarrollo.

En la fotografía 5 se aprecia una vista de la laguna Chuchón, ubicada en la cordillera La Viuda, donde nace el río Chillón.

\section{Fotografía 5 \\ Cuenca alta del río Chillón}

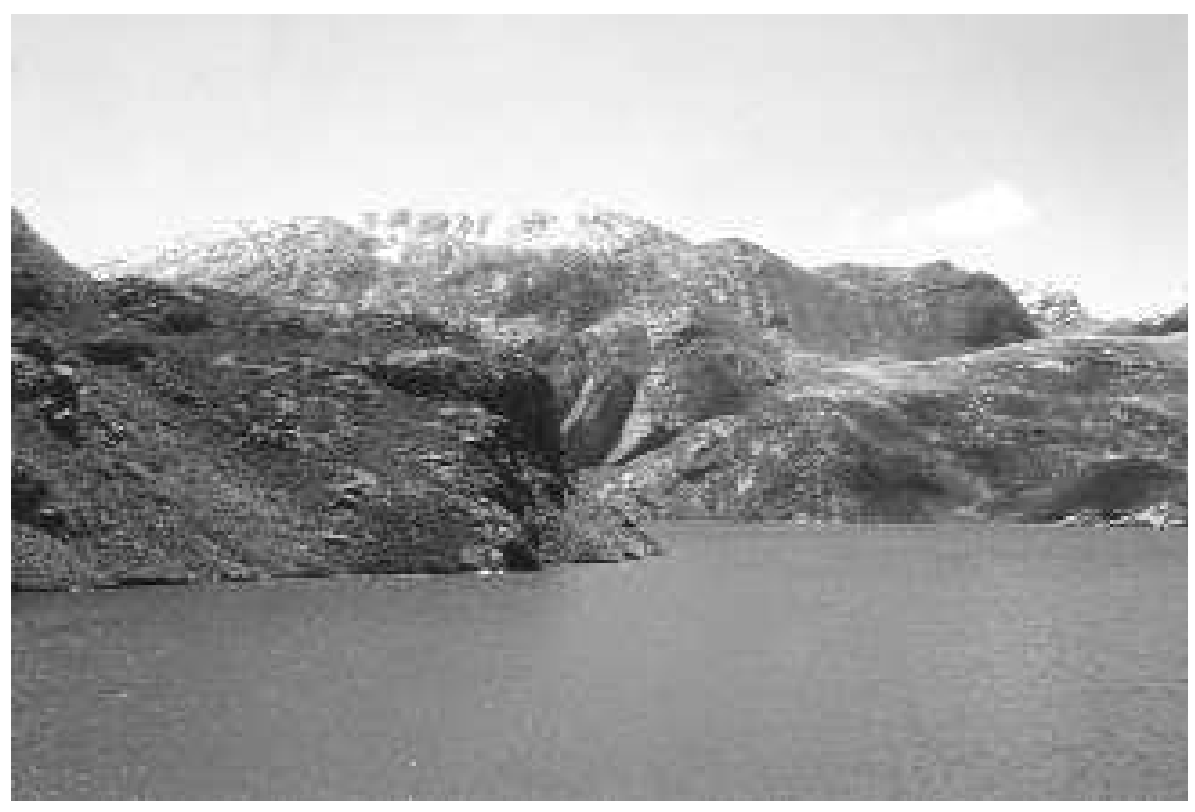

Fuente: Universidad de Lima, Centro de Estudios Ambientales, 1997. 


\section{ASPECTOS AMBIENTALES}

A pesar de su importancia y del interés de las autoridades por conformar la Autoridad Autónoma del Río Chillón, esta cuenca ha venido deteriorándose progresivamente y sus valores se han opacado por una gran cantidad de factores de variada magnitud.

La cuenca baja aparece como el ámbito más contaminado. Este sector está sufriendo un proceso de deterioro ambiental como resultado de una falta de planeación urbano-rural, por la inexistencia de condiciones sanitarias básicas en gran parte de esta cuenca, el crecimiento poblacional desordenado, la falta de cultura ambiental, entre otros. Sin embargo, el nivel de contaminación físicoquímica y microbiológica en el agua aún es reversible y manejable.

\subsection{Calidad del agua}

Para el monitoreo de calidad del agua llevado a cabo en el estudio titulado "Evaluación preliminar con fines productivos en la cuenca del río Chillón", se consideraron cuatro estaciones: una a la salida de la laguna de Chuchón, otra en el río Chillón (km 96, en Canta), la tercera en el puente Panamericana Norte y, finalmente, una cuarta en el puente Néstor Gambeta.

La temperatura más baja se registró en el agua a la salida de la laguna de Chuchón $\left(9.1^{\circ} \mathrm{C}\right)$ y la más alta $\left(26.0^{\circ} \mathrm{C}\right)$ se reportó en el puente Panamericana Norte. Una temperatura superior a $15^{\circ} \mathrm{C}$ favorece el desarrollo de microorganismos, a la vez que puede intensificar olores y sabores; por el contrario, una temperatura menor de $10^{\circ} \mathrm{C}$ modera las reacciones químicas y bioquímicas. En el gráfico 1 se muestran las temperaturas que se presentan a lo largo del río Chillón.

\section{Gráfico 1}

Temperatura del río Chillón

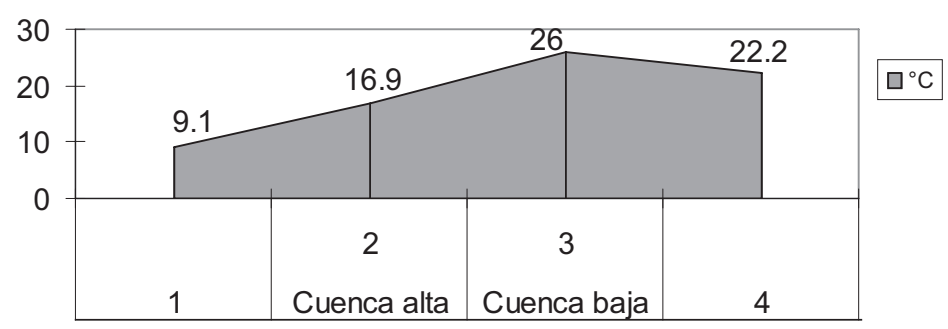

Estaciones de muestreo. 
El mayor valor de la demanda bioquímica de oxígeno $\left(\mathrm{DBO}_{5}\right)$ se obtuvo también en la estación del puente Panamericana Norte (76 $\mathrm{mg} / \mathrm{l})$, lo que excede en cinco veces lo permitido por la Ley General de Aguas para un río cuyas aguas son de uso agropecuario (para irrigación y bebida de animales). Como se sabe, valores altos de $\mathrm{DBO}_{5}$ indican la presencia de materia orgánica considerable y, por lo tanto, niveles bajos de oxígeno disuelto, indispensable para la vida acuática en los cuerpos de agua. En el gráfico 2 se aprecia este parámetro y su comportamiento a lo largo de la cuenca, específicamente en los puntos que se han tomado como muestra.

\section{Gráfico 2}

Demanda bioquímica de oxígeno (DBO)

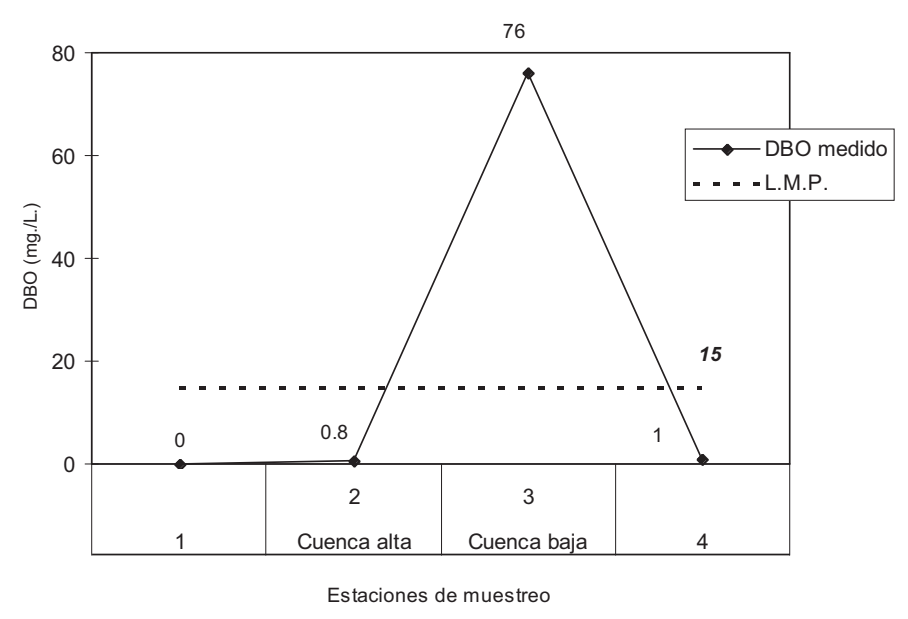

Los resultados de laboratorio del Centro Panamericano de Ingeniería Sanitaria y Ciencias del Ambiente (Cepis) evidencian contaminación microbiológica por residuos fecales humanos y animales. Los valores oscilan de $2 \mathrm{NMP} / 100 \mathrm{~mL}$ en el rebose de la laguna de Chu-

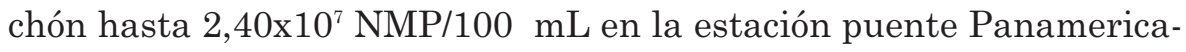
na Norte, ubicado en la cuenca baja. La tendencia relevante en la evaluación de este parámetro es el aumento de la carga bacteriana a medida que se acerca al área de mayor densidad poblacional. Esto se explica por la escasez de servicios sanitarios básicos en los asentamientos humanos, las descargas de aguas residuales y la presencia de resi- 
duos sólidos domésticos arrojados al río por los pobladores asentados en la zona. Este análisis se desprende del gráfico 3, donde se muestran los resultados microbiológicos en tres estaciones de monitoreo, exceptuando la primera, a la salida de la laguna de Chuchón.

Con respecto a la calidad fisicoquímica del agua en la cuenca alta del río Chillón, esta muestra condiciones favorables para actividades de pesca y recreativas. Si se tiene en cuenta que la evaluación fue realizada en época de bajo caudal, se puede prever que la calidad del agua del río será notablemente superior en época de alto caudal.

Gráfico 3

Coliformes fecales

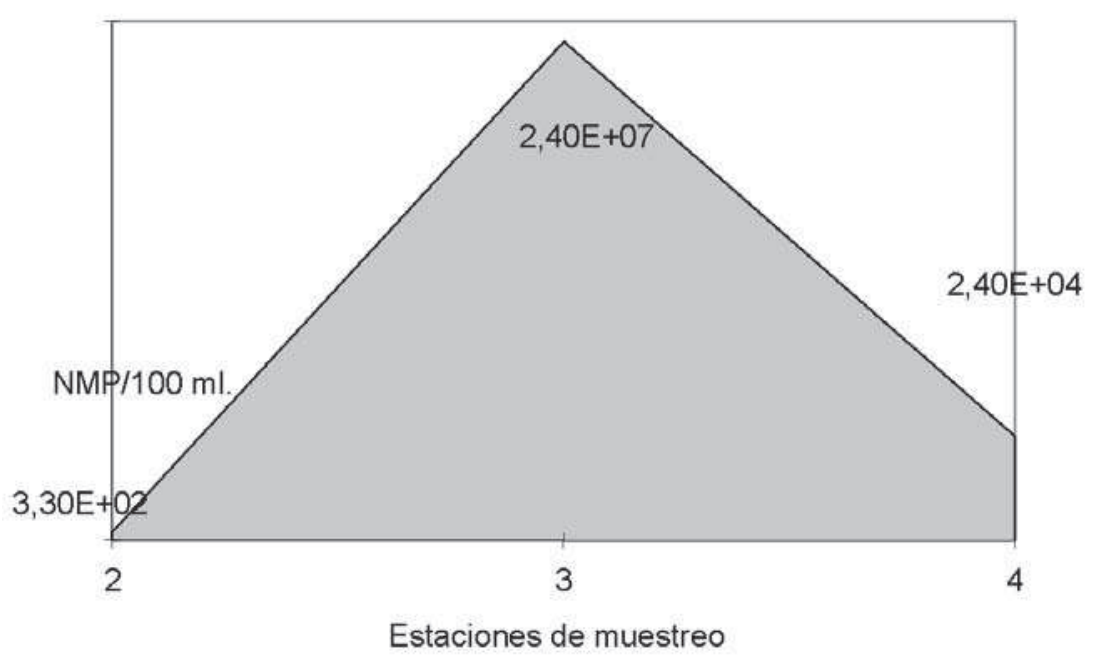

\subsection{Manejo de residuos sólidos}

En lo que respecta al manejo de los residuos sólidos en la cuenca baja, solo el 71\% de los residuos sólidos generados por la población son destinados a rellenos sanitarios y el $29 \%$ restante tiene diferentes destinos, entre los que se cuentan los botaderos a cielo abierto, las chancherías clandestinas, los lugares de acopio de recicladores informales y los lugares donde estos residuos son quemados.

La crianza de cerdos en condiciones sanitarias deplorables, la infiltración de lixiviados provenientes de la descomposición de los residuos 
sólidos dispuestos inadecuadamente y el escurrimiento superficial, ocasionan una contaminación gradual de la napa freática, así como un intenso daño a la calidad del agua de río.

En general, en gran parte de la cuenca baja se aprecia:

- Acumulación de residuos sólidos en sus riberas y la quema de estos.

- Reciclaje clandestino de metales.

- Vertido de desagües domésticos y descargas industriales, sin ningún tratamiento previo.

- Criaderos de cerdos.

- Abuso en la utilización de pesticidas.

- Mala calidad del agua para consumo doméstico, industrial y otros usos en la metrópoli.

- Descontrolado proceso de expansión urbana, lo cual ha terminado por devorar casi la totalidad del área potencialmente agrícola.

En las partes media y alta de la cuenca se aprecia:

- Mal uso del suelo, pues no se utilizan tierras adecuadas para la producción agropecuaria.

- Métodos agrícolas que no son sostenibles ni técnica ni económicamente.

- El sobrepastoreo que, junto a otros factores, genera paulatinamente una mayor erosión y la pérdida de fertilidad de los suelos.

- Precarias condiciones de conservación de importantes restos histórico-arqueológicos.

Pero, sin duda, uno de los más graves problemas que ha sufrido la cuenca ha sido el fenómeno El Niño de 1998. Este fenómeno se caracteriza por ser una contracorriente marina cálida, que avanza desde el océano Pacífico norte hacia las costas del Perú, Ecuador y Chile, acompañada de bruscos cambios físicos que afectan las condiciones en el mar y la atmósfera, siendo el más notorio las lluvias intensas.

Los efectos de El Niño de 1998 fueron considerables. A continuación se enumeran algunos: 
- El elevado caudal de las aguas y la falta de defensas ribereñas originaron la inundación de cientos de hectáreas de cultivo en la parte baja.

- La ubicación de asentamientos humanos en zonas de riesgo que obligaron a la voladura del puente Inca, a fin de ensanchar el cauce del río y evitar mayores daños.

- La población damnificada directamente por el fenómeno El Niño de 1998, ascendió a 675 habitantes, y la población en riesgo por inundaciones a 15.000 personas.

- El desborde del río y la continua sucesión de huaicos en las partes media y alta de la cuenca arrasaron con cultivos y viviendas de los pobladores, que no tuvieron otra alternativa que ocupar zonas consideradas patrimonio histórico.

- La devastación casi total de las quebradas de Soccos, Hornillos, Carrizal, Huerta Vieja, Pucará, Alpacarrosa, Pampachecta, entre otras. En las fotografías 6 y 7 se pueden apreciar los efectos del fenómeno en mención.

\section{Fotografía 6 \\ Afectación de la cuenca media por el fenómeno EI Niño}

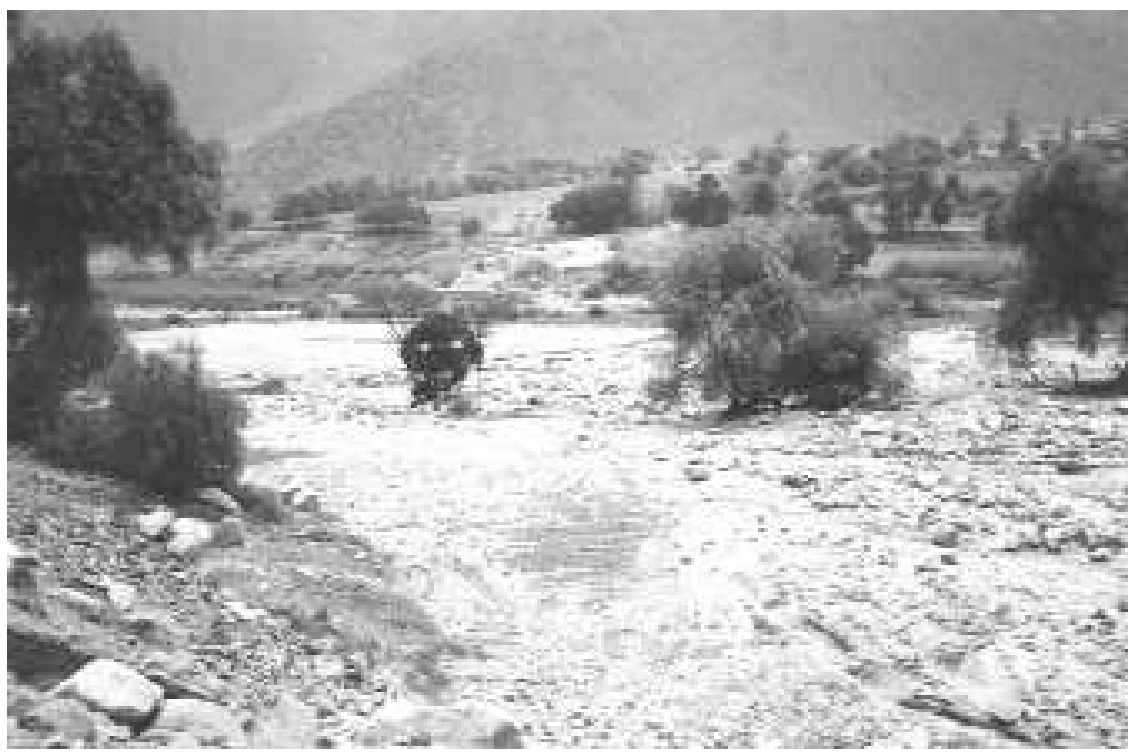

Fuente: Universidad de Lima, Centro de Estudios Ambientales, marzo de 1998. 


\section{Fotografía 7}

Efectos del fenómeno El Niño en la cuenca media del río Chillón

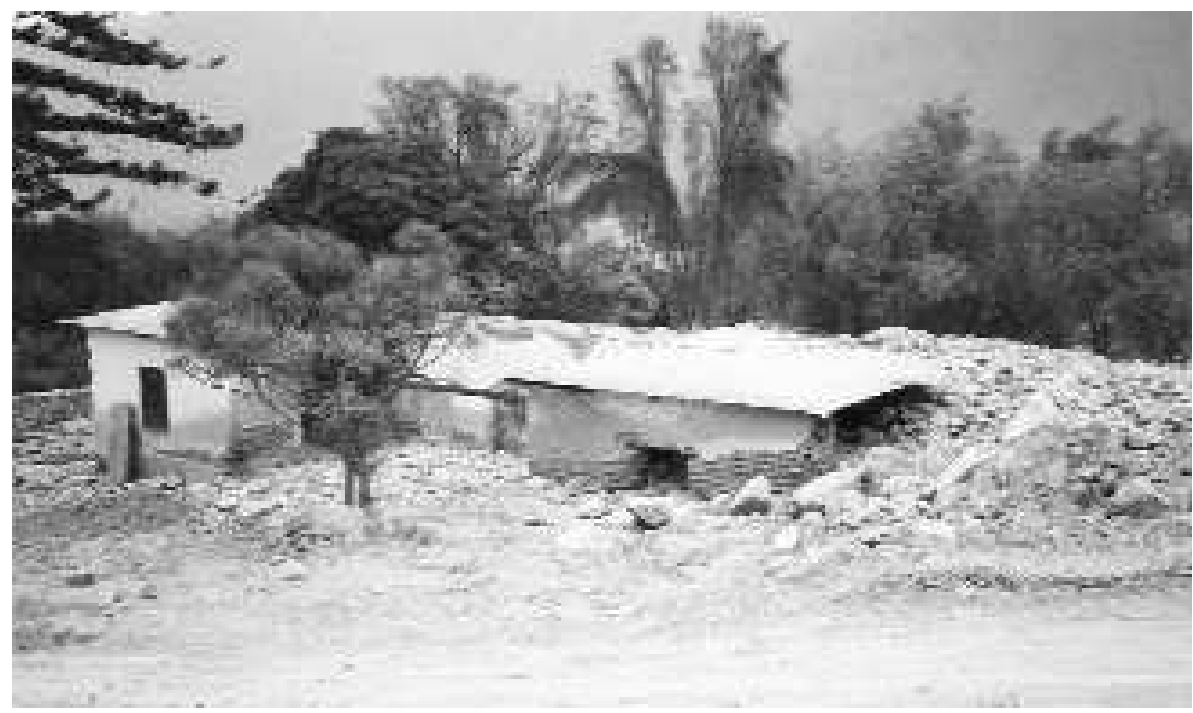

Fuente: Universidad de Lima, Centro de Estudios Ambientales, marzo de 1998.

\section{ALGUNAS ALTERNATIVAS DE RECUPERACIÓN Y DESARROLLO}

- Recuperación del bosque ribereño a lo largo de toda la cuenca, como un medio para minimizar las inundaciones.

- Protección de las riberas con gaviones y con una reforestación, previniendo futuros huaicos y deslizamientos.

- Aplicación de la Ley Marco del Sistema Nacional de Gestión Ambiental, Ley 28245, por parte de los gobiernos locales, con el fin de que organicen y desarrollen un programa de gestión y manejo de residuos sólidos para evitar su disposición inadecuada y que así se minimice la contaminación del río.

- Erradicación de las construcciones en zonas de riesgo por desastres naturales, señaladas por el Instituto Nacional de Defensa Civil (Indeci).

- Aplicación de la normatividad ambiental vigente en el sector industrial, con el fin de evitar las descargas industriales y el manejo inadecuado de los residuos que vienen contaminando la parte de la cuenca del río donde se encuentran ubicadas las industrias. 
- Elaboración de un plan de gestión y ordenamiento territorial por parte de los gobiernos locales para el control del avance de las poblaciones hacia zonas agrícolas.

- Estructuración de un eje turístico que articule las áreas de paisaje natural, el patrimonio histórico-monumental y la infraestructura turística de recreación.

- Incidencia en políticas integrales de desarrollo que permitan dotar de mayores y mejores herramientas técnicas y financieras al productor de la cuenca, que lo hagan competitivo y con presencia en el mercado.

La posibilidad de revertir esta tendencia al deterioro solo será posible si pobladores, autoridades e instituciones trabajan en conjunto hacia un mismo objetivo: rescatar la importancia social, económica y ambiental de la cuenca del río Chillón.

Precisamente, la Universidad de Lima contribuye con este esfuerzo mediante propuestas para descontaminar la cuenca baja, mejorar el uso de los recursos naturales y elevar la calidad de vida de los pobladores del área del Chillón.

\section{BIBLIOGRAFÍA}

Brack Egg, Antonio. "Tratado de Libre Comercio y biodiversidad del Perú". Informe anual sobre los derechos económicos, sociales y culturales en el perú, 2004: Lo que se debe conocer antes de decidir. El impacto del libre comercio en los derechos humanos en el Perú. Lima: Aprodeh/Cedal, 2005.

Consejo Nacional del Ambiente. "Perú: Vulnerabilidad frente al cambio climático. Aproximaciones a la experiencia con el fenómeno El Niño. Lima: Conam, octubre de 1999.

Instituto Nacional de Estadística e Informática. Perú: Estadísticas del medio ambiente. Lima: INEI, 2000.

Olarte N., Bertha. "Plan integral de gestión ambiental de residuos sólidos en el distrito de Carabayllo, Lima". Tesis para optar el grado de magíster en ingeniería sanitaria y ambiental. Cali, Colombia: Universidad del Valle, 2002. 
Universidad de Lima. [Video]: "Efectos del fenómeno El Niño en la cuenca del río Chillón”. Lima: Universidad de Lima, Centro de Estudios Ambientales/ DUDEA. Octubre de 1998.

—. "Estudio preliminar con fines productivos en la cuenca del río Chillón”. Lima: Universidad de Lima, Centro de Estudios Ambientales/Municipalidad de Lima. Agosto de 1997. 